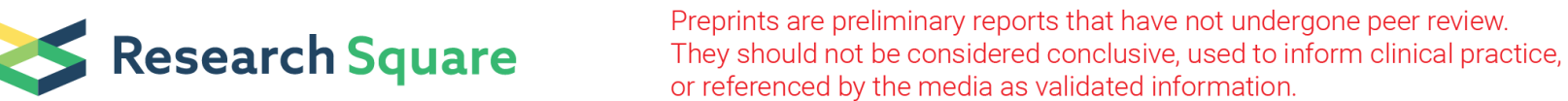

\section{Effect of Different Washing Solutions on Soil Enzyme Activity and Microbial Community in Agricultural Soil Severely Contaminated With Cadmium}

\section{Yu Zhang}

Nanjing University of Information Science and Technology

Chunfa Wu ( $\square$ wchf1680@sina.com)

Nanjing University of Information Science and Technology https://orcid.org/0000-0001-5058-7792

\section{Shaopo Deng}

Nanjing Institute of Environmental Sciences

Jinlu Zhang

Nanjing University of Information Science and Technology

Jinyu Hou

Institute of Soil Science Chinese Academy of Sciences

Chong Wang

Nanjing University of Information Science and Technology

Zhaocong Fu

Nanjing University of Information Science and Technology

\section{Research Article}

Keywords: Soil washing, Remediation effect, Ecological effect, Enzyme activities, Microbial community

Posted Date: December 6th, 2021

DOI: https://doi.org/10.21203/rs.3.rs-1063888/v1

License: (c) (i) This work is licensed under a Creative Commons Attribution 4.0 International License.

Read Full License

Version of Record: A version of this preprint was published at Environmental Science and Pollution Research on March 19th, 2022. See the published version at https://doi.org/10.1007/s11356-022-197346. 


\section{Abstract}

Soil enzyme activities and microbial communities have a good response to the remediation effect of heavy metal-contaminated soils. To evaluate the effect of three commonly used washing agents, ferric chloride (FC), ethylenediamine-tetra- methylenephosphonic acid (EDTMP) and ethylenediamine tetraacetic acid (EDTA) on soil enzyme activities and microbial community in cadmium (Cd)contaminated agricultural soil collected around the mining area. The soil enzyme activities, microbial community, chemical forms of $\mathrm{Cd}$ and some physicochemical properties of the soil washed with different washing solutions were determined after two months incubation. The results showed that the three washing solutions had moderate removal efficiencies (22.83\%-37.56\%) for $\mathrm{Cd}$ in the tested soil and the breakdown product of EDTMP has a certain stabilizing effect on $\mathrm{Cd}$. The geometric mean and the integrated total enzyme activity index showed that soil washing with FC and EDTA were more beneficial to the restoration of biochemical functions than that with EDTMP. The relative abundance of Gemmatimonadetes in the soil washed with EDTA was significantly higher than that with FC and EDTMP. The relative abundance of Firmicutes in the soil washed with EDTMP was significantly increased, and the relative abundance of Bacteroidetes in the soil washed with FC was significantly decreased. Pearson correlation analysis and redundancy analysis (RDA) indicated that the three washing solutions affected soil enzyme activities and microbial community by altering soil nutrient, total $\mathrm{Cd}$ concentration and $\mathrm{Cd}$ fractions in soils.

\section{Introduction}

It is well known that metal mining activity discharges large amounts of heavy metals (HMs) into the surrounding environment, including soils, and metal mining activity has become one of the major anthropogenic sources of HMs in soil. Due to the rapid development of metal mining and metal processing in recent decades, soil contaminated with HMs occurs widely in China (Luo et al. 2012, Mkhinini et al. 2020, Zhang et al. 2013a, Zhao et al. 2015). Cadmium (Cd) is a typical and common HM pollutant in agricultural soils surrounding mining areas (Du et al. 2020). Cd contamination in agricultural soils has become a serious challenge for food security in China due to the high mobility and bioavailability of $\mathrm{Cd}$ (Chen et al. 2018). Previous studies have shown that agricultural soils surrounding mining areas are always severely contaminated with Cd and other HMs (Helmfrid et al. 2015, Weerasundara et al. 2018), and it resulted in Cd concentrations in agricultural products generally exceeded the national standard (Du et al. 2020).

Chemical washing is one of the common remediation technologies that applied to agricultural soils contaminated with HMs including Cd (Wang et al. 2019a). It can permanently remove Cd from soils by the physical and chemical effects, such as desorption, chelation, dissolution, and fixation of the washing solutions (Rui et al. 2020). The common washing agents include inorganic washing agents, chelators, surfactants, etc. (Khalid et al. 2017, Wang \&Chen 2019). Ferric chloride (FC) is a chloride solution, ethylenediamine tetraacetic acid (EDTA) is a chelating agent, and ethylenediamine-tetramethylenephosphonic acid (EDTMP) is a photodegradable chelating agent. Previous studies showed that 
the three washing agents have good Cd-extraction efficiency (Feng et al. 2020, Guo et al. 2016, Makino et al. 2016, Makino et al. 2008).

Soil enzyme activity is a potential indicator of soil health due to its high sensitivity to external interference(Tan et al. 2014). Sucrase, urease, acid phosphatase and catalase are common soil enzymes and their activities are closely related to soil carbon $(C)$, nitrogen $(N)$, phosphorus $(P)$ cycling and soil redox capacity, respectively(Eivazi \&Tabatabai 1977, Feyzi et al. 2020, Hu et al. 2014, Yang et al. 2016). The structure and diversity of soil microorganisms communities are also important biological indicators of soil health (Wang et al. 2019b). Previous studies have reported that soil Cd decreased the activities of soil enzymes and significantly affected the diversity of the microbial community(Wang et al. 2007, Xu et al. 2013). Therefore, soil enzyme activity and microbial community may have the potential for assessing the remediation effect of HMs contaminated soils.

Soil washing may not only remove some HMs pollutants in the soil but also lead to the loss of nutrients and major elements, the activation of soil HMs and the residue of washing agents, which may lead to significant changes in soil enzymes and microbial communities (Wei et al. 2020, Zhang et al. 2013b). Therefore, in the evaluation of remediation effect of HM-contaminated soil, we should not only consider the removal efficiency and the ecological risk of HMs, but also pay attention to the changes of soil enzyme activities and microbial community. Many studies on soil enzymes and microbial communities in soils contaminated with HMs have been conducted (Han et al. 2020a, Liu et al. 2020a, Njoku et al. 2020), however, to our knowledge, few studies have reproted the effect of different washing solutions on enzyme activity and microbial community in agricultural soils contaminated with HMs. The objectives of this study wereto evaluate the impact of the three washing agents (FC, EDTA and EDTMP) on the activities of the four soil enzymes(catalase, acid phosphatase, urease and sucrase) and microbial community and to study their potential influence factors.

\section{Materials And Methods}

\subsection{Soil and washing agents}

The test soils were collected from the topsoil $(0-20 \mathrm{~cm})$ of farmland near a non-ferrous metal smelter in Baiyin City, Gansu Province, China $\left(104^{\circ} 14.622^{\prime} \mathrm{E}, 36^{\circ} 32.322^{\prime} \mathrm{N}\right)$. The soil samples were air-dried, ground and then sieved through a 2-mm sieve.

The concentration of $\mathrm{Cd}$ in the tested soil was as high as $40.82 \mathrm{mg} \mathrm{kg}^{-1}$, far exceeds the risk intervention values $\left(3.00 \mathrm{mg} \mathrm{kg}^{-1}\right)$ of the Soil Environmental Quality Risk Control Standard for Soil Contamination of Agricultural Land (GB 15618-2018), and the tested soil was severely contaminated by Cd.

FC and EDTA were purchased from Sinopharm Chemical Reagent Co., Ltd, and EDTMP was purchased from MERYER Co., Ltd. All the three agents were of analytical-reagent grade.

\subsection{Soil washing and incubation procedures}


$1 \mathrm{~L}$ Glass beakers containing $80 \mathrm{~g}$ of soil were prepared for batch washing experiments, followed by the addition of $10 \mathrm{mmol} \mathrm{L}^{-1}$ EDTMP, FC, and EDTA solutions at a soil-solution ratio of 1:5 (w/v) that was selected based on the previous studies (Guo et al. 2018, Wei et al. 2020). Deionized water was added to the control treatment (CK). The beakers were shaken with an ultrasonic vibrating machine at $200 \mathrm{~W}$ for 45 min. After vibration, the supernatant was drained off. The washed soil was then rinsed with deionized water at a soil-solution ratio of 1:5 (w/v). Each experiment was replicated three times.

After washing, the soil was transferred to a $100 \mathrm{~mL}$ glass beaker and then incubated for two months according to previous studies (Rajaie et al. 2006, Wu et al. 2015a).

\subsection{Soil analysis}

After two months incubation, a proportion of soils was air-dried for soil analysis. Soil pH was determined with a pH meter (PHS-3C, INESA, China) at a soil-water ratio of 1:2.5. Soil conductivity (EC) was measured with a conductivity meter (DDS-307A, INESA, China) at a soil/water ratio of 1:5. Soil organic matter (SOM) was measured by the potassium dichromate oxidation-oil bath heating method (Nelson 1996). The cation exchange capacity (CEC) was analysed after soil extraction using ammonium acetate (Sumner \&Miller 1996). The total nitrogen content (TN) was determined using the semi-micro Kjeldahl method (Bremner 1960). Soil total phosphorus content (TP) was measured using the Mo-Sb antispectrophotography method (Bao 2000). Soil available potassium (AK) was measured using the ammonium acetate extraction-flame photometric method (Bao 2000). The available P content (AP) was measured based on the method of Olsen et al. (Olsen 1954). The total Cd was measured using ICP-MS after digestion with $\mathrm{HCl}-\mathrm{HNO}_{3}-\mathrm{HClO}_{4}$.

\subsection{Chemical forms of Cd}

The chemical forms of $\mathrm{Cd}$ in the washed soil, including exchangeable (F1), bound to carbonates (F2), bound to Fe-Mn oxides (F3), bound to organic matter (F4) and residual (F5), were analysed using a modified Tessier's sequential extraction procedure (Zhu et al. 2018).

\subsection{Soil enzymes}

Soil catalase activity was measured by potassium permanganate titration, soil urease activity was measured by sodium phenol sodium hypochlorite colorimetry, soil sucrase activity was measured by the 3,5-dinitrosalicylic acid method, and soil acid phosphatase activity was analysed by sodium diphenyl phosphate colorimetry.

The effect of washing solutions on soil enzyme activities was evaluated using the geometric mean (GMean) index and the integrated total enzyme activity index (TEI) proposed by Tan et al. (Tan et al. 2014).

The GMean and the TEl were calculated using the following equations:

GMean $=\sqrt[4]{\text { catalase } \times \text { acidphosphatase } \times \text { sucrase } \times \text { urease }}(1)$ 
TEI $=\sum_{n=1}^{i} \underset{X_{i}}{\frac{X_{i}}{-}}(n=1,2,3,4)(2)$

where $X_{i}$ is the activity of soil enzyme $i$ and $\bar{X}_{i}$ is the mean activity of enzyme $i$ in all samples.

\subsection{Bacteria community}

Microbial DNA was extracted from $0.5 \mathrm{~g}$ soil using a FastDNA spin kit, and the quality and concentration of extracted DNA were tested by a NanoDrop 1000 spectrophotometer (Thermo Fisher, Waltham, MA).

High-throughput sequencing was carried out by Shanghai Majorbio Bio-pharm Technology Co., Ltd. The primers 515F (5'-barcode-GTGCCAGCMGCCGCGG-3') and 907R (5'- CCGTCAATTCMTTTRAGTTT-3') were used to amplify the V4-V5 region of the bacterial 16S ribosomal RNA gene. According to the manufacturer's instructions, the amplified products were extracted from a $2 \%$ agarose gel and purified by an AxyPrep DNA Gel Extraction Kit (Axygen Biosciences, Union City, CA, U.S.).

Sequences were clustered into operational taxonomic units (OTUs) of $\geq 97 \%$ similarity using the Deblur denoising algorithm, which removes noise caused by sequencing errors(R.Cole's et al. 2009). The phylogenetic affiliation of each 16S rRNA gene sequence was analyzed by the RDP Classifier (http://rdp.cme.msu.edu/) at a confidence threshold of 70\% (Caporaso et al. 2010).

\subsection{Statistical Analyses}

The Chao1 richness index and Shannon diversity index were evaluated using the pheatmap package (version 1.0.12) in $\mathrm{R}$ (version 1.30.1). Bioinformatic analysis was performed using the OmicStudio tools at https://www.omicstudio.cn/tool. One-way analysis of variance (ANOVA) and Tukey HSD were used to determine the statistical significance $(p<0.05)$ of differences between treatments. The correlation matrix of soil environmental factors, soil enzyme activities and bacterial diversity was drawn by Origin 2021.

\section{Results}

\subsection{Soil properties}

The physicochemical properties of the soils treated with different washing solutions are presented in Table 1. Compared with CK, the EC of soils washing with FC and EDTA significantly increased, however, the EC of soil washed with EDTMP significantly decrease. The concentrations of TN and TP in the soil washed with EDTMP were significantly higher than the other soils. However, compared with the CK, AK and AP were significantly decreased after washing with FC, EDTA and EDTMP. There was no significant difference in $\mathrm{pH}, \mathrm{CEC}$ or SOM among all treatments.

Table 1 Selected physicochemical properties of the soil with different treatments

Data are presented as mean values \pm SE $(n=3)$ 


\begin{tabular}{|c|c|c|c|c|}
\hline Soil properties & CK & FC & EDTA & EDTMP \\
\hline Soil pH & $7.44 \pm 0.07^{a}$ & $7.29 \pm 0.13^{a}$ & $7.41 \pm 0.07^{a}$ & $7.25 \pm 0.13^{a}$ \\
\hline $\mathrm{EC}, \mu \mathrm{S} \mathrm{cm}-1$ & $1287 \pm 0.94^{c}$ & $1471 \pm 0.47^{a}$ & $1307 \pm 0.94^{b}$ & $1162 \pm 1.70^{d}$ \\
\hline SOM, $\mathrm{g} \mathrm{kg}^{-1}$ & $15.1 \pm 1.64^{\mathrm{a}}$ & $14.14 \pm 0.85^{a}$ & $14.37 \pm 0.52^{\mathrm{a}}$ & $16.27 \pm 0.90^{\mathrm{a}}$ \\
\hline CEC, $\mathrm{cmol} \mathrm{kg}^{-1}$ & $8.03 \pm 0.12^{a}$ & $7.97 \pm 0.29^{a}$ & $7.43 \pm 0.12^{\mathrm{a}}$ & $7.93 \pm 0.37^{a}$ \\
\hline Total $\mathrm{N}, \mathrm{mg} \mathrm{kg}^{-1}$ & $337 \pm 0.55^{b}$ & $279 \pm 1.57^{b}$ & $328 \pm 0.55^{b}$ & $514 \pm 36.43^{a}$ \\
\hline Total $P, \mathrm{~g} \mathrm{~kg}^{-1}$ & $0.82 \pm 0.01^{b}$ & $0.87 \pm 0.04^{b}$ & $0.85 \pm 0.03^{b}$ & $2.80 \pm 0.28^{a}$ \\
\hline Available $\mathrm{K}, \mathrm{mg} \mathrm{kg}^{-1}$ & $194 \pm 1.63^{a}$ & $178 \pm 1.70^{b}$ & $177 \pm 0.82^{b}$ & $168 \pm 1.63^{c}$ \\
\hline Available $P, \mathrm{mg} \mathrm{kg}^{-1}$ & $60.68 \pm 4.10^{\mathrm{a}}$ & $42.14 \pm 2.79^{b}$ & $46.93 \pm 2.68^{b}$ & $37.45 \pm 2.07^{b}$ \\
\hline
\end{tabular}

\subsection{Removal efficiencies and chemical forms of Cd}

Table 2 Concentration of $\mathrm{Cd}$ in different chemical form in the soil with different treatments

Data are presented as mean values $\pm \operatorname{SE}(n=3)$

\begin{tabular}{|lllllll|}
\hline & $\mathrm{F} 1\left(\mathrm{mg} \mathrm{kg}^{-1}\right)$ & $\begin{array}{l}\mathrm{F} 2(\mathrm{mg} \\
\left.\mathbf{k g}^{-1}\right)\end{array}$ & $\mathrm{F3}\left(\mathrm{mg} \mathrm{kg}^{-1}\right)$ & $\begin{array}{l}\mathrm{F} 4(\mathbf{m g} \\
\left.\mathbf{k g}^{-1}\right)\end{array}$ & $\begin{array}{l}\mathrm{F} 5(\mathrm{mg} \\
\left.\mathbf{k g}^{-1}\right)\end{array}$ & Total Cd \\
\hline CK & $14.27 \pm 0.22^{\mathrm{a}}$ & $7.32 \pm 0.31^{\mathrm{a}}$ & $16.20 \pm 0.11^{\mathrm{a}}$ & $0.61 \pm 0.14^{\mathrm{b}}$ & $0.57 \pm 0.14^{\mathrm{b}}$ & $40.82 \pm 0.68^{\mathrm{a}}$ \\
\hline FC & $7.00 \pm 0.23^{\mathrm{C}}$ & $6.12 \pm 0.09^{\mathrm{b}}$ & $13.83 \pm 0.28^{\mathrm{b}}$ & $0.61 \pm 0.08^{\mathrm{b}}$ & $0.55 \pm 0.06^{\mathrm{b}}$ & $31.50 \pm 0.59^{\mathrm{b}}$ \\
\hline EDTA & $7.95 \pm 0.28^{\mathrm{b}}$ & $3.85 \pm 0.08^{\mathrm{c}}$ & $11.86 \pm 0.21^{\mathrm{C}}$ & $0.55 \pm 0.09^{\mathrm{b}}$ & $0.56 \pm 0.06^{\mathrm{b}}$ & $26.69 \pm 0.38^{\mathrm{c}}$ \\
\hline EDTMP & $8.08 \pm 0.23^{\mathrm{b}}$ & $3.82 \pm 0.12^{\mathrm{c}}$ & $10.26 \pm 0.35^{\mathrm{d}}$ & $1.73 \pm 0.09^{\mathrm{a}}$ & $0.95 \pm 0.09^{\mathrm{a}}$ & $25.49 \pm 0.11^{\mathrm{c}}$ \\
\hline
\end{tabular}

Different letters indicate significant difference between treatments in the same soil at $P<0.05$ following Tukey HSD test.

In this study, three washing solutions and deionized water (as a control treatment) were used to simulate the washing of tested soil. The three washing solutions had significant removal effects on Cd after a short washing period. The removal efficiencies of EDTMP and EDTA were $37.56 \%$ and $36.04 \%$, respectively, and were significantly higher than FC (22.83\%) and CK (1.26\%). 
The chemical forms of $\mathrm{Cd}$ in the soils washed with different washing solutions are shown in Table 2. The speciation of Cd in the soils was mostly F3, F1 and F2, followed by F5, and F4. Compared to those in CK, the F1, F2 and F3 fractions of Cd in soil decreased after washing with the three washing solutions. However, after washing with EDTMP, the F4 and F5 fractions were significantly increased compared to CK.

\subsection{Soil enzyme activities}

The activities of enzymes in soils washed with different washing solutions are shown in Figure 1. Compared with CK, the activity of acid phosphatase in soil washed with FC was significantly increased, the activities of acid phosphatase and urease in soil washed with EDTA were significantly increased, and the activity of urease in soil washed with EDTMP was significantly increased but catalase decreased. The FC solution significantly increased the activity of soil acid phosphatase, the EDTA solution increased activities of acid phosphatase and urease, and the EDTMP solution increased the activity of sucrase activity but decreased catalase.

The mean GMean index values and the mean TEl values of all treatments were CK, 0.86 and 3.58; EDTMP, 0.87 and 3.81 ; EDTA, 1.03 and 4.26 ; and FC, 1.04 and 4.35 , respectively.

\subsection{Soil microbial community}

Table 3 Alpha diversity indexes of bacterial communities

\begin{tabular}{|lllll|}
\hline & CK & FC & EDTMP & EDTA \\
\hline Chao1 & 11731 & 13497 & 13758 & 16568 \\
\hline Shannon & 6.9 & 6.8 & 6.7 & 7.2 \\
\hline
\end{tabular}

In this study, 120000 high-quality bacterial sequences were generated. The sequences were further clustered into 50430 OTUs with $97 \%$ similarity. The bacteria were from 41 phyla, 148 classes, 298 orders, 499 families and 864 genera. The coverage rate of bacteria was over $96 \%$, which is suitable to represent the diversity of bacteria in all samples. As shown in Tab. 3, the FC, EDTA and EDTMP treatments increased the Chao1 index.

The differences in the relative abundance of microorganisms in the different treatments can be intuitively observed with a heat map (Fig. 3a). As shown in Fig. 3a, at the phylum level, the microbial community structure of the control and washed soil was mainly concentrated in Proteobacteria (26.9\%-31.3\%), Acidobacteria (12.8\%- 16.8\%), Gemmatimonadetes (8.1\%-14.1\%), Actinobacteria (9.0\%-12.3\%), Chloroflexi (11.7\%-13.6\%), Bacteroidetes (3.2\%-5.9\%), Planctomycetes (3.0\%-4.5\%), Firmicutes (0.8\%-12.1\%), and Nitrospirae (3.0\%-4.5\%). At the phylum level, the EDTA, FC and CK treatments had highly similar community composition, but the EDTMP treatment was different from them. The proportions of various bacterial phyla in each treatment were significantly different. Overall, the relative abundance of 
Gemmatimonadetes in soil washed with EDTA was significantly higher than that with FC and EDTMP. The relative abundance of Firmicutes in soil washed with EDTMP significantly increased, and the relative abundance of Bacteroidetes in soil washed with FC significantly decreased (Fig. 3b).

LDA effect size (LEfSe) analysis examines the biomarkers for the soil bacterial communities (Fig. 4). The results indicated that 14 bacterial genera with an LDA level $\geq 4.0$ differed. Firmicutes, Clostridia,

Clostridiales, Symbiobacteriaceae and Symbiobacterium were biomarkers in the soil washed with EDTMP, Burkholderiales, Oxalobacteraceae and Ramlibacterwere biomarkers in the soil washed with FC, and Gemmatimonadetes, MND1, Acidobacteria_6, Gemm_3 and iii1_15 were biomarkers in the soil washed with EDTA.

\subsection{Relationship between environmental factors and microbial community}

RDA results are used to show the relationship between environmental factors and soil microbial communities and the relationship between soil enzymes and the microbial community (Fig. 5). As shown in Fig. 5 a, the first two axes of the RDA plot explained $25.52 \%$ and $18.86 \%$ of the variation in the soil microbial communities, respectively. TN and TP had a positive correlation with the EDTMP treatment and Firmicutes, Bacteroidetes and Verrucomicrobia. Soil pH had a positive correlation with the EDTA treatment, Gemmatimonadetes, Nitrospirae, Proteobacteria and Chlorobi. F2 and EC had a positive correlation with the FC treatment, Acidobacteria, Fibrobacteres, Chloroflexi and Actinobacteria. In addition, the correlations between Firmicutes and Bacteroidetes and the EDTMP treatment and between Gemmatimonadetes and the EDTA treatment were consistent with the LDA results (Fig. 4).

\subsection{Relationship between activities of the soil enzyme and bacteria community}

As shown in Fig. 5 b, the first two axes explained $25.30 \%$ and $18.35 \%$ of the variation in the soil microbial communities, respectively. Urease and sucrase activities had a positive correlation with the EDTMP treatment, Firmicutes, Bacteroidetes and Verrucomicrobia. Acid phosphatase and catalase activities had a positive correlation with the FC treatment, Actinobacteria, Fibrobacteres, Acidobacteria, Proteobacteria, Chlorobi and Chloroflexi.

\section{Discussion}

\subsection{Effect of washing solutions on $\mathrm{Cd}$ in soil}

The concentrations of $\mathrm{Cd}$ in the soils washing with the FC, EDTA and EDTMP solutions were significantly lower than that in $\mathrm{CK}$ (Tab. 1), indicating that the three washing agents have certain removal effects on Cd. However, previous studies that showed EDTA could remove $93 \%$ of $\mathrm{Cd}$ at a soil-solution ratio of 1:5 for $2 \mathrm{~h}$ (Wang et al. 2018); FC could remove $62.9 \%$ of $\mathrm{Cd}$ at a soil-solution ratio of $1: 2$ for $1 \mathrm{~h}$ (Zhai et al. 2018), and EDTMP could remove $65.63 \%$ of $C d$ at a soil-solution ratio of 1:10 for $2 \mathrm{~h}$ (Feng et al. 2020). 
The moderate removal rates of the three washing agents may due to the high concentration of $\mathrm{Cd}$ in the soil and the relatively low concentration of washing agent in the washing solutions.

The $\mathrm{Cd}$ in the soils washing with the FC, EDTA, and EDTMP solutions as well as the CK was fractionated to further investigate how the chemical forms of $\mathrm{Cd}$ are affected by soil washing. F3, F4 and F5 generally exist in a stable state and have relatively small adverse effects on the environment; however, F1 and F2 have higher activity, which leads to greater environmental risk (Wu et al. 2015b, Yang et al. 2018, Zhang et al. 2017). The concentration of the active content of HMs in soil plays an important role in the ability of plants to absorb HMs. The higher the active content of HMs in soil, the easier it is for plants to absorb these HMs (Han et al. 2020a). Furthermore, a previous study has shown that the uptake of Cd is closely related to active fractions of $\mathrm{Cd}$ in soil (Li et al. 2017). In our study, all three washing solutions can significantly reduce the active components of $\mathrm{Cd}$ and reduce the environmental risk.

The EDTMP treatment significantly increased the F4 and F5 fractions, this can be attributed to the effect of the photodegradation of EDTMP. It has been proven that under experimental conditions, phosphonates are converted into orthophosphates, especially in the presence of iron and at acidic pH. EDTMP is photodegraded by UV into orthophosphates (Lesueur et al. 2005). Cd can precipitate with orthophosphates as $\mathrm{Cd}_{3}\left(\mathrm{PO}_{4}\right)_{2}$ in soils containing an excessive concentration of $\mathrm{Cd}$ (Mcgowen et al. 2001). In addition, EDTMP treatment significantly increased the activity of soil urease, which can catalyse the hydrolysis of urea to produce $\mathrm{NH}_{4}{ }^{+}$and $\mathrm{CO}_{3}{ }^{2-}$ and combine with $\mathrm{Cd}^{2+}$ to produce $\mathrm{CdCO}_{3}$, thereby reducing effective fractions of $\mathrm{Cd}$ in soil (Wang et al. 2020).

\subsection{Effect of washing solutions on soil enzyme activities}

Enzyme activity exhibits high sensitivity and rapid responses to soil quality and can be used as a performance index after soil washing (Beiyuan et al. 2018). Previous studies have confirmed that HMs can decrease the activities of soil sucrase, urease, phosphatase and catalase (Qin et al. 2020, Tang et al. 2020). Changes in soil physicochemical properties, such as SOM, nutrients, and $\mathrm{pH}$, may be the main reasons for the changes in soil enzyme activities. Pearson correlation analysis showed that the activities of soil catalase and acid phosphatase were positively correlated with EC (Fig. 2), indicating that EC had a positive effect on enzyme activities which is consistent with the report by Tang et al. (Tang et al. 2020). The changes in the levels of soil nutrient elements such as N, P and $\mathrm{K}$ also significantly affected soil enzyme activities. For example, soil urease activity was positively correlated with the TN and TP $(P<$ 0.01), which was consistent with previous studies (Im et al. 2015, Mkhinini et al. 2020, Qin et al. 2010). In addition, the chemical forms of $\mathrm{Cd}$ also strongly regulate soil enzyme activity. Soil catalase was negatively correlated with F4 $(P<0.01)$ and F5 $(P<0.01)$ and positively correlated with F3 $(P<0.01)$. Previous study demonstrated that moderate $C d$ stress can promote the activity of some soil enzymes and the promotion becomes inhibition when the concentration of $\mathrm{Cd}$ in soil is further increased (Wang et al. 2019a). In this study, the increase of some enzyme activities may be related to the concentration of $\mathrm{Cd}$ decreased to the level that promoted enzyme activity. 
The geometric mean index can directly show the change of global enzyme activity (Xu et al. 2021), and it has been satisfactorily used to evaluate the quality of HMs-contaminated soils (Hinojosa et al. 2004, Lessard et al. 2014). TEl can be used to easily compare the combined enzyme activity and the quality of each soil sample (Tan et al. 2014). Compared with that in CK, the GMean index increased after washing with the three washing solutions. This indicated that chemical washing in our study might benefit the biochemical functions of agricultural soil contaminated with $\mathrm{Cd}$. However, soil washing with EDTMP exhibited significantly decreased catalase activity, which led to a lower GMean index value than those of FC and EDTA. The result for the TEl index was the same as that for the GMean index, which indicated that these two indexes are reliable for the comprehensive evaluation of the global enzyme response after soil washing.

\subsection{Effect of washing solutions on soil microbial community}

After washing, the physiochemical properties of the soil changed, and the survival conditions for Cdresistant dominant bacteria were disrupted, which made it difficult for some soil microorganisms to adapt to the new environment (Zhai et al. 2018). In this study, Proteobacteria were predominant in all treated soils, indicating that Proteobacteria were the most HMs-tolerant microorganisms in severely contaminated soils, which was consistent with a previous study (Eva-Maria et al. 2011). In addition, some researchers have suggested that Bacteroidetes may possess metal-resistant properties (Haller et al. 2011, $\mathrm{Ni}$ et al. 2016), Gemmatimonadetes have been identified to be associated with HM-contaminated soils (Ni et al. 2016), and Firmicutes also have a strong tolerance to extreme conditions (Hortal et al. 2013). RDA indicated that F2 had strong effects on the soil bacterial community. The bioavailable fraction, rather than the total content of $\mathrm{HMs}$, is a major factor influencing bacterial community changes because bioavailable forms are easily used by surrounding microorganisms which was consistent with previous studies (Hou et al. 2017, Muhlbachova et al. 2015). Furthermore, the RDA results also indicated that TP and TN were two main factors affecting the microbial community. TN plays a key role in cell metabolic processes, such as energy metabolism, protein synthesis, and cell division (Liu et al. 2020b). RDA results showed that the relative abundance of Bacteroidetes was significantly positively correlated with TN, which was consistent with the previous study (Bian et al. 2018). Previous studies have also shown that changes in the $\mathrm{P}$ concentration in soil are the main factor leading to changes in microbial community composition (Wei et al. 2020). In addition, bacteria belonging to Proteobacteria and Firmicutes can use nutrient sources to increase soil quality (Han et al. 2020b). EDTA contains many sources of $\mathrm{N}$ and $\mathrm{C}$, and EDTMP contains $\mathrm{C}, \mathrm{N}$ and $\mathrm{P}$, which may benefit $\mathrm{HM}$ remediation of agricultural soil.

The Chao1 index and Shannon index were used to evaluate the alpha diversity of the soil microorganism communities (Tab. 3). The Chao1 index is an indicator of species richness in ecology (Chao 1984), and a higher Chao1 indicates a larger number of species and a variety of species that exist in a sample. The Chao1 indexes of FC and EDTA were higher than that of EDTMP, indicating that the bacterial community richness under FC and EDTA was higher than that under EDTMP. The Shannon index is an abundancebased diversity index that is widely used in many disciplines (Chao et al. 2014), and a higher Shannon

Page 10/21 
index indicates higher community diversity within a sample. All the washed soil samples had a larger number of microbial taxa than the control sample. Nevertheless, the Shannon index was not significantly different between the washed and control soil samples, which was indicative of the stability of ecosystem productivity and the functions of the soil microbiome (Zheng et al. 2016).

Based on the above analysis, it is reasonable to conclude that the three washing solutions can significantly change the soil microbial community by changing the soil physicochemical properties and the concentration and fractionation of $\mathrm{Cd}$.

\subsection{The relationship between soil washing, soil enzyme and bacteria}

In this study, soil washing may have affected enzyme activities in two ways. First, the washing agent may have had a direct impact on the activities of soil enzymes. Second, the washing agent may have caused changes in the soil bacterial community, resulting in changes in its secretions and metabolism and affecting its enzyme production behaviour. However, our results do not provide any information about the functions of these specific microorganisms. Therefore, it is necessary to use molecular biological methods to further analyse their function and to better understand the mechanism of the bacteria community regulating soil ecological functions after washing.

\section{Conclusion}

This work evaluated the impact of the three commonly used washing agents on soil enzyme activities and microbial community in agricultural soil severely contaminated with $\mathrm{Cd}$. All three washing solutions had certain removal effects on $\mathrm{Cd}$ and their removal efficiency followed the order of EDTMP>EDTA>FC. All three washing solutions can significantly reduce F1, F2 and F3. In addition, the breakdown product of EDTMP had a certain stabilizing effect on soil Cd.

Soil enzyme activities had a significant change after soil washing. The activity of acid phosphatase in soil washed with FC was significantly increased, the activities of acid phosphatase and urease in soil washed with EDTA were significantly increased, and the activity of urease in soil washed with EDTMP was significantly increased but catalase decreased. The GMean index and the TEl showed that FC resulted in the best global enzyme response after soil washing. After soil washing, the Chao 1 index of bacteria increased, and the microbial community structure changed. Proteobacteria, Firmicutes and Gemmatimonadetes can be used as markers for the soil microbial community response to soil washing, and TP, TN, EC and F2 were confirmed to be the four vital parameters that shaped the bacterial communities. These results could provide a new perspective on the assessment of the ecological effect of soil washing on agricultural soils severely contaminated with $\mathrm{Cd}$.

\section{Abbreviations}

Cd, cadmium; 
HMs, heavy metals;

EC, electrical conductivity;

SOM, soil organic matter;

CEC, cation exchange capacity;

FC, ferric chloride;

EDTA, ethylenediamine tetraacetic acid;

EDTMP, ethylenediamine-tetra-methylenephosphonic acid;

F1, exchangeable Cd;

F2, Cd bound to carbonates;

F3, Cd bound to iron and manganese oxides;

F4, Cd bound to organic matter;

F5, residual Cd.

\section{Declarations}

Ethics approval and consent to participate

Not applicable

Consent for publication

Not applicable

\section{Availability of data and materials}

The datasets used and/or analysed during the current study are available from the corresponding author on reasonable request.

\section{Competing interests}

The authors declare that they have no competing interests.

\section{Funding}

This study was supported in part by and the National Key Research and Development Project of China (Grant no. 2019YFC1804704) and the Graduate Research and Innovation Projects of Jiangsu Province 
(KYCX21_1021).

\section{Authors' contributions}

Overarching research goals and aims were designed by Chunfa Wu. Material preparation, data collection and analysis were performed by Yu Zhang, Jinlu Zhang, Shaopo Deng, Jinyu Hou, Chong wang and Zhaocong Fu. The first draft of the manuscript was written by Yu Zhang and Chunfa Wu reviewed and commented on previous versions of the manuscript. All authors read and approved the final manuscript.

\section{Acknowledgements}

The authors are very grateful to all the colleagues who helped with the collection and analysis of the soil samples.

\section{References}

1. Bao S (2000) Soil Agricultural Chemical Analysis (in chinese). China Agriculture Press, Beijing

2. Beiyuan J, Lau AYT, Tsang DCW, Zhang W, Kao C-M, Baek K, Ok YS, Li X-D (2018) Chelant-enhanced washing of CCA-contaminated soil: Coupled with selective dissolution or soil stabilization. Sci Total Environ 612:1463-1472

3. Bian F, Zhong Z, Zhang X, Yang C, Su W (2018) Remediation of Heavy Metal Contaminated Soil by Moso Bamboo (Phyllostachys edulis) Intercropping with Sedum plumbizincicola and the Impact on Microbial Community Structure. Linye Kexue/Scientia Silvae Sinicae 54:106-116

4. Bremner JM (1960) Determination of nitrogen in soil by the Kjeldahl method. Journal of Agricultural ence 55:11-33

5. Caporaso J et al (2010) QIIME allows analysis of high-throughput community sequencing data. Nat Methods 7:335-336

6. Chao A (1984) : Nonparametric estimation of the number of classes in a population.Scandinavian Journal of Statistics11

7. Chao A, Chiu C-H, Jost L (2014) : Unifying Species Diversity, Phylogenetic Diversity, Functional Diversity, and Related Similarity and Differentiation Measures Through Hill Numbers. Annual Review of Ecology, Evolution, and Systematics 45, 297-324

8. Chen H, Yang X, Wang P, Wang Z, Li M, Zhao F (2018) Dietary cadmium intake from rice and vegetables and potential health risk: A case study in Xiangtan, southern China. Sci Total Environ 639:271-277

9. Du B, Zhou J, Lu B, Zhang C, Li D, Zhou J, Jiao S, Zhao K, Zhang H (2020) Environmental and human health risks from cadmium exposure near an active lead-zinc mine and a copper smelter, China. Sci Total Environ 720:137585

10. Eivazi F, Tabatabai MA (1977) Phosphatases in soils. Soil Biol Biochem 9:167-172 
11. Eva-Maria B, Sebastian B, Georg MAD, Kirsten B K (2011) Heavy Metal Tolerance of Fe(III)-Reducing Microbial Communities in Contaminated Creek Bank Soils. Appl Environ Microbiol 77:3132-3136

12. Feng W, Zhang S, Zhong Q, Wang G, Pan X, Xu X, Zhou W, Li T, Luo L, Zhang Y (2020) Soil washing remediation of heavy metal from contaminated soil with EDTMP and PAA: Properties, optimization, and risk assessment. J Hazard Mater 381:120997

13. Feyzi H, Chorom M, Bagheri G (2020) Urease activity and microbial biomass of carbon in hydrocarbon contaminated soils. A case study of cheshmeh-khosh oil field, Iran. Ecotoxicol Environ Saf 199:110664

14. Guo X, Wei Z, Wu Q, Li C, Qian T, Zheng W (2016) Effect of soil washing with only chelators or combining with ferric chloride on soil heavy metal removal and phytoavailability: Field experiments. Chemosphere 147:412-419

15. Guo X, Zhao G, Zhang G, He Q, Wei Z, Zheng W, Qian T, Wu Q (2018) Effect of mixed chelators of EDTA, GLDA, and citric acid on bioavailability of residual heavy metals in soils and soil properties. Chemosphere 209:776-782

16. Haller L, Tonolla M, Zopfi J, Peduzzi R, Wildi W, Poté J (2011) Composition of bacterial and archaeal communities in freshwater sediments with different contamination levels (Lake Geneva, Switzerland). Water Res 45:1213-1228

17. Han H, Cai H, Wang X, Hu X, Chen Z, Yao L (2020a) Heavy metal-immobilizing bacteria increase the biomass and reduce the $\mathrm{Cd}$ and $\mathrm{Pb}$ uptake by pakchoi (Brassica chinensis L.) in heavy metalcontaminated soil. Ecotoxicol Environ Saf 195:110375

18. Han H, Wu X, Yao L, Chen Z (2020b) Heavy metal-immobilizing bacteria combined with calcium polypeptides reduced the uptake of $\mathrm{Cd}$ in wheat and shifted the rhizosphere bacterial communities. Environ Pollut 267:115432

19. Helmfrid I, Salihovic S, van Bavel B, Wingren G, Berglund M (2015) Exposure and body burden of polychlorinated biphenyls (PCB) and metals in a historically contaminated community. Environ Int 76:41-48

20. Hinojosa MB, García-Ruíz R, Viñegla B, Carreira JA (2004) Microbiological rates and enzyme activities as indicators of functionality in soils affected by the Aznalcóllar toxic spill. Soil Biol Biochem 36:1637-1644

21. Hortal S, Bastida F, Armas C, Lozano YM, Moreno JL, García C, Pugnaire FI (2013) Soil microbial community under a nurse-plant species changes in composition, biomass and activity as the nurse grows. Soil Biol Biochem 64:139-146

22. Hou D, Wang K, Liu T, Wang H, Lin Z, Qian J, Lu L, Tian S (2017) Unique Rhizosphere Microcharacteristics Facilitate Phytoextraction of Multiple Metals in Soil by the Hyperaccumulating Plant Sedum alfredii. Environ Sci Technol 51:5675-5684

23. Hu XF, Jiang Y, Shu Y, Hu X, Liu L, Luo F (2014) Effects of mining wastewater discharges on heavy metal pollution and soil enzyme activity of the paddy fields. J Geochem Explor 147:139-150 
24. Im J, Yang K, Jho EH, Nam K (2015) Effect of different soil washing solutions on bioavailability of residual arsenic in soils and soil properties. Chemosphere 138:253-258

25. Khalid S, Shahid M, Niazi NK, Murtaza B, Bibi I, Dumat C (2017) A comparison of technologies for remediation of heavy metal contaminated soils. J Geochem Explor 182:247-268

26. Lessard I, Sauvé S, Deschênes L (2014) Toxicity response of a new enzyme-based functional diversity methodology for Zn-contaminated field-collected soils. Soil Biol Biochem 71:87-94

27. Lesueur C, Pfeffer M, Fuerhacker M (2005) Photodegradation of phosphonates in water. Chemosphere 59:685-691

28. Li Y, Chen Y-F, Zhang G-J, Liu Y, Zhou C-B (2017) A numerical procedure for modeling the seepage field of water-sealed underground oil and gas storage caverns. Tunn Undergr Space Technol 66:5663

29. Liu C, Lin H, Li B, Dong Y, Yin T (2020a) Responses of microbial communities and metabolic activities in the rhizosphere during phytoremediation of Cd-contaminated soil. Ecotoxicol Environ Saf 202:110958

30. Liu H, Wang C, Xie Y, Luo Y, Sheng M, Xu F, Xu H (2020b) Ecological responses of soil microbial abundance and diversity to cadmium and soil properties in farmland around an enterprise-intensive region. J Hazard Mater 392:122478

31. Luo X, Yu S, Zhu Y, Li X (2012) Trace metal contamination in urban soils of China. Sci Total Environ 421-422:17-30

32. Makino T, Takano H, Kamiya T, Itou T, Sekiya N, Inahara M, Sakurai Y (2008) Restoration of cadmium-contaminated paddy soils by washing with ferric chloride: Cd extraction mechanism and bench-scale verification. Chemosphere 70:1035-1043

33. Makino T, Maejima Y, Akahane I, Kamiya T, Takano H, Fujitomi S, Ibaraki T, Kunhikrishnan A, Bolan N (2016) A practical soil washing method for use in a Cd-contaminated paddy field, with simple on-site wastewater treatment. Geoderma 270:3-9

34. Mcgowen SL, Basta NT, Brown GO (2001) Use of Diammonium Phosphate to Reduce Heavy Metal Solubility and Transport in Smelter-Contaminated Soil. J Environ Qual 30:493

35. Mkhinini M, Boughattas I, Alphonse V, Livet A, Gıustı-Mıller S, Bannı M, Bousserrhıne N (2020) Heavy metal accumulation and changes in soil enzymes activities and bacterial functional diversity under long-term treated wastewater irrigation in East Central region of Tunisia (Monastir governorate). Agric Water Manage 235:106150

36. Muhlbachova G, Sagova-Mareckova M, Omelka M, Szakova J, Tlustos P (2015) The influence of soil organic carbon on interactions between microbial parameters and metal concentrations at a longterm contaminated site. Sci Total Environ 502:218-223

37. Nelson DW (1996) Total carbon, organic carbon, and organic matter. Methods of Soil Analysis 9:961-1010

38. Ni C, Horton DJ, Rui J, Henson MW, Jiang Y, Huang X, Learman D (2016) High concentrations of bioavailable heavy metals impact freshwater sediment microbial communities. Ann Microbiol 
66:1003-1012

39. Njoku KL, Asunmo MO, Ude EO, Adesuyi AA, Oyelami AO (2020) The molecular study of microbial and functional diversity of resistant microbes in heavy metal contaminated soil. Environmental Technology \& Innovation 17:100606

40. Olsen SR (1954) Estimation of available phosphorus in soils by extraction with sodium bicarbonate. 939:18-19

41. Qin S, Hu C, Wang Y, Li X, He X (2010) Tillage Effects on Intracellular and Extracellular Soil Urease Activities Determined by an Improved Chloroform Fumigation Method. Soil Sci 175:568-572

42. Qin X, Liu Y, Huang Q, Zhao L, Xu Y (2020) Effects of Sepiolite and Biochar on Enzyme Activity of Soil Contaminated by Cd and Atrazine. Bull Environ Contam Toxicol 104:642-648

43. Cole's R, Wang J, Cardenas Q, Fish E, Chai J, Farris B, Kulam-Syed-Mohideen R, McGarrell AS, Marsh D, Garrity T, Tiedje G J (2009) The Ribosomal Database Project: Improved Alignments and New Tools for rRNA Analysis. Nucleic Acids Res 37:141-145

44. Rajaie M, Karimian N, Maftoun M, Yasrebi J, Assad M (2006) Chemical Forms of Cadmium in Two Calcareous Soil Textural Classes as Affected by Application of Cadmium-Enriched Compost and Incubation Time. Geoderma 136:533-541

45. Rui D, Wu W, Zhang H, Li G, Wang S, Ito Y (2020) Optimization analysis of heavy metal pollutants removal from fine-grained soil by freeze-thaw and washing technology. Cold Reg Sci Technol 173:103025

46. Sumner ME, Miller WP (1996) Cation exchange capacity and exchange coefficients. Methods of Soil Analysis Chemical Methods

47. Tan X, Xie B, Wang J, He W, Wang X, Wei G (2014) : County-scale spatial distribution of soil enzyme activities and enzyme activity indices in agricultural land: implications for soil quality assessment. The Scientific World Journal 2014, 535768

48. Tang J, Zhang L, Zhang J, Ren L, Zhou Y, Zheng Y, Luo L, Yang Y, Huang H, Chen A (2020) Physicochemical features, metal availability and enzyme activity in heavy metal-polluted soil remediated by biochar and compost. Sci Total Environ 701:134751

49. Wang G, Zhang S, Zhong Q, Xu X, Li T, Jia Y, Zhang Y, Peijnenburg W, Vijver MG (2018) Effect of soil washing with biodegradable chelators on the toxicity of residual metals and soil biological properties. Sci Total Environ 625:1021-1029

50. Wang J, Lu Y, Shen G (2007) Combined effects of cadmium and butachlor on soil enzyme activities and microbial community structure. Environ Geol 51:1221-1228

51. Wang K, Liu Y, Song Z, Khan ZH, Qiu W (2019a) : Effects of biodegradable chelator combination on potentially toxic metals leaching efficiency in agricultural soils. Ecotoxicology and Environmental Safety 182, 109399.1-109399.8

52. Wang Q, Chen J (2019) Recovery of EDTA from soil-washing wastewater with calcium-hydroxideenhanced sulfide precipitation. Chemosphere 237:124286 
53. Wang S, Li T, Zheng Z, Chen HYH (2019b) Soil aggregate-associated bacterial metabolic activity and community structure in different aged tea plantations. Sci Total Environ 654:1023-1032

54. Wang T, Wang S, Tang X, Fan X, Yang S, Yao L, Li Y, Han H (2020) Isolation of urease-producing bacteria and their effects on reducing $\mathrm{Cd}$ and $\mathrm{Pb}$ accumulation in lettuce (Lactuca sativa L.). Environ Sci Pollut Res 27:8707-8718

55. Weerasundara L, Magana-Arachchi DN, Ziyath AM, Goonetilleke A, Vithanage M (2018) Health risk assessment of heavy metals in atmospheric deposition in a congested city environment in a developing country: Kandy City, Sri Lanka. J Environ Manage 220:198-206

56. Wei H, Liu Y, Chao Y, Tsang DCW, Zhao N, Liu K, Zhang W, Qiu R (2020) Recovery of the biological function of ethylenediaminetetraacetic acid-washed soils: Roles of environmental variations and microbes. Sci Total Environ 715:137032

57. Wu C, Yan S, Zhang H, Luo Y (2015a) Chemical forms of cadmium in a calcareous soil treated with different levels of phosphorus-containing acidifying agents. Soil Research 53:105-111

58. Wu Q, Cui Y, Li Q, Sun J (2015b) Effective removal of heavy metals from industrial sludge with the aid of a biodegradable chelating ligand GLDA. J Hazard Mater 283:748-754

59. Xu XH, Liu CY, Li RY, Wang XR (2013) Impacts of cadmium stress on soil microbial and enzyme activities under laboratory conditions. Journal of Food Agriculture Environment 11:1730-1734

60. Xu Z, Yang Z, Zhu T, Shu W, Geng L (2021) Ecological improvement of antimony and cadmium contaminated soil by earthworm Eisenia fetida: Soil enzyme and microorganism diversity. Chemosphere 273:129496

61. Yang J, Yang F, Yang Y, Xing G, Deng C, Shen Y, Luo L, Li B, Yuan H (2016) A proposal of "core enzyme" bioindicator in long-term $\mathrm{Pb}$-Zn ore pollution areas based on topsoil property analysis. Environ Pollut 213:760-769

62. Yang ZH, Dong CD, Chen CW, Sheu YT, Kao CM (2018) Using poly-glutamic acid as soil-washing agent to remediate heavy metal-contaminated soils. Environ Sci Pollut Res 25:5231-5242

63. Zhai X, Li Z, Huang B, Luo N, Huang M, Zhang Q, Zeng G (2018) Remediation of multiple heavy metal-contaminated soil through the combination of soil washing and in situ immobilization. Sci Total Environ 635:92-99

64. Zhang H, Gao Y, Xiong H (2017) Removal of heavy metals from polluted soil using the citric acid fermentation broth: a promising washing agent. Environ Sci Pollut Res 24:1-9

65. Zhang T, Liu J-M, Huang X-F, Xia B, Su C-Y, Luo G-F, Xu Y-W, Wu Y-X, Mao Z-W, Qiu R-L (2013a) Chelant extraction of heavy metals from contaminated soils using new selective EDTA derivatives. $J$ Hazard Mater 262:464-471

66. Zhang T, Liu JM, Huang XF, Xia B, Su CY, Luo GF, Xu YW, Wu YX, Mao ZW, Qiu RL (2013b) Chelant extraction of heavy metals from contaminated soils using new selective EDTA derivatives. J Hazard Mater 262:464-471

67. Zhao FJ, Ma Y, Zhu YG, Tang Z, Mcgrath SP (2015) Soil Contamination in China: Current Status and Mitigation Strategies. Environmental Science\&Technology 49:750 
68. Zheng J, Chen J, Pan G, Liu X, Zhang X, Li L, Bian R, Cheng K, Zheng J (2016) Biochar decreased microbial metabolic quotient and shifted community composition four years after a single incorporation in a slightly acid rice paddy from southwest China. Sci Total Environ 571:206-217

69. Zhu H, Wu C, Wang J, Zhang X (2018) The effect of simulated acid rain on the stabilization of cadmium in contaminated agricultural soils treated with stabilizing agents. Environmental Science Pollution Research 25:17499-17508

\section{Figures}

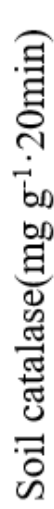
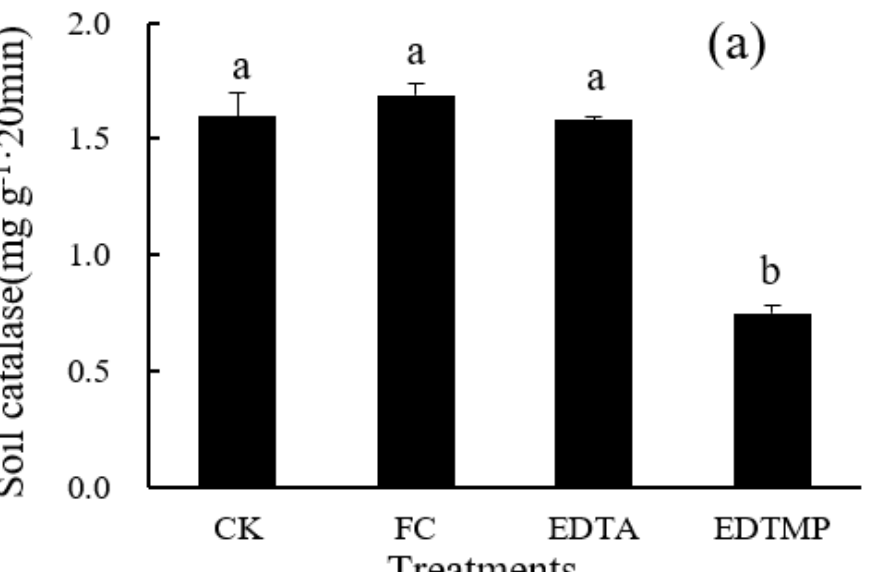

Treatments

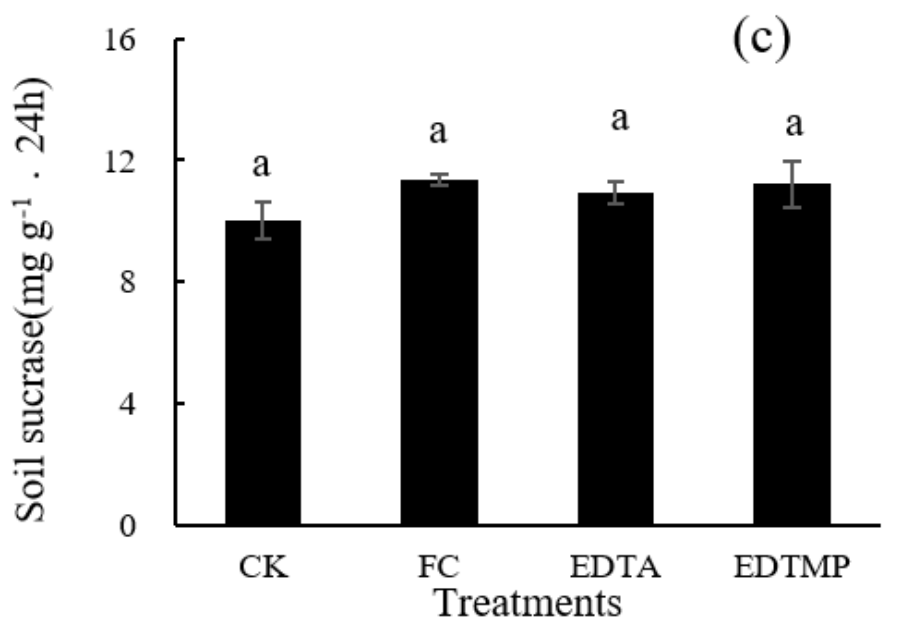

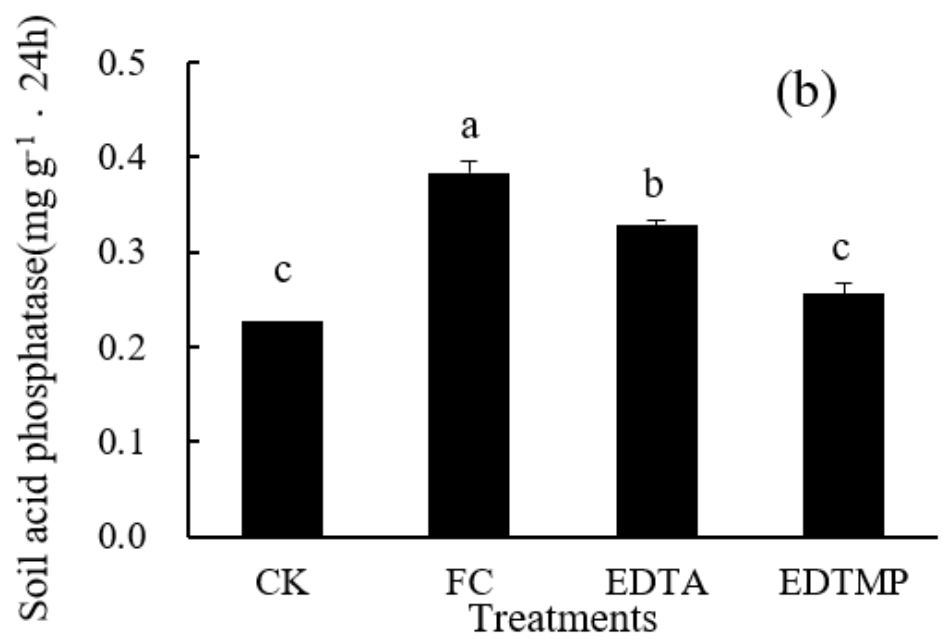

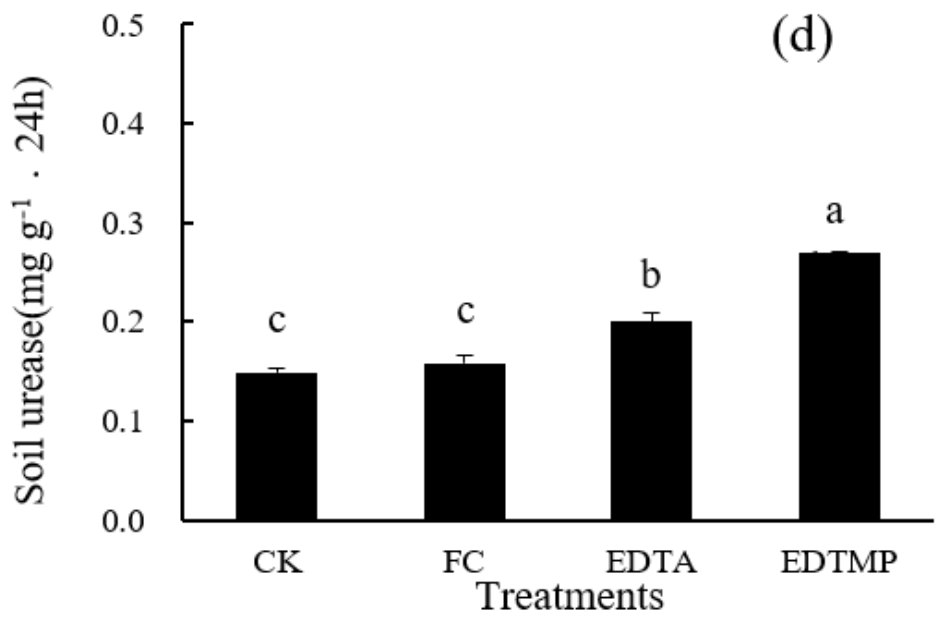

Figure 1

Changes of soil enzymatic activities. (a)catalase, (b) acid phosphatase, (c) sucrase, (d) urease 


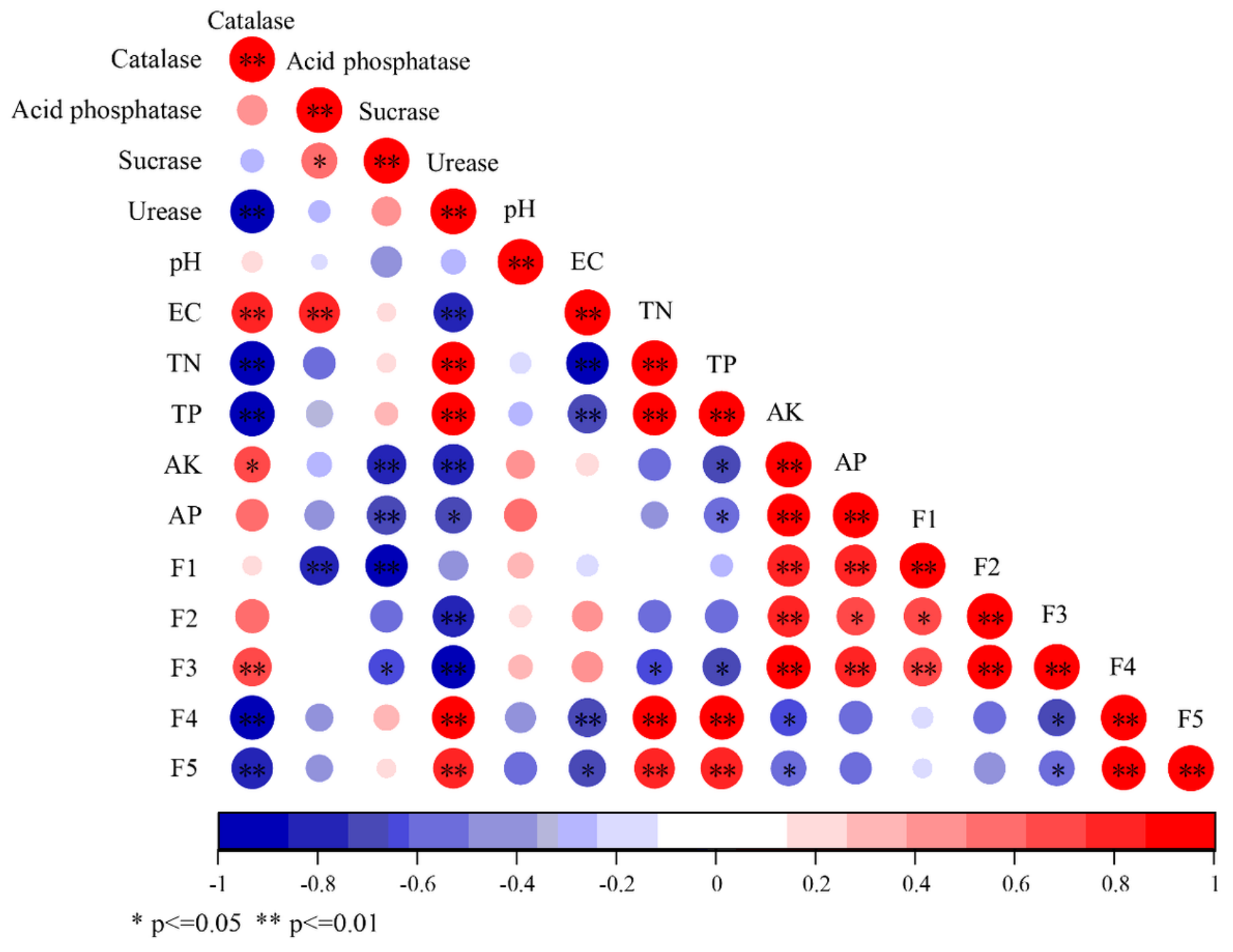

Figure 2

Matrix of Pearson's rank correlation coefficients between soil environment factors and enzyme activities. Correlation coefficients ( $r$ values) are indicated by different colors and sizes of circle. Red represents positive correlation, blue represents negative correlation, and the larger the circle diameter is, the stronger the correlation is. ${ }^{*} p<0.05 ;{ }^{*} \mathrm{p}<0.01$ 


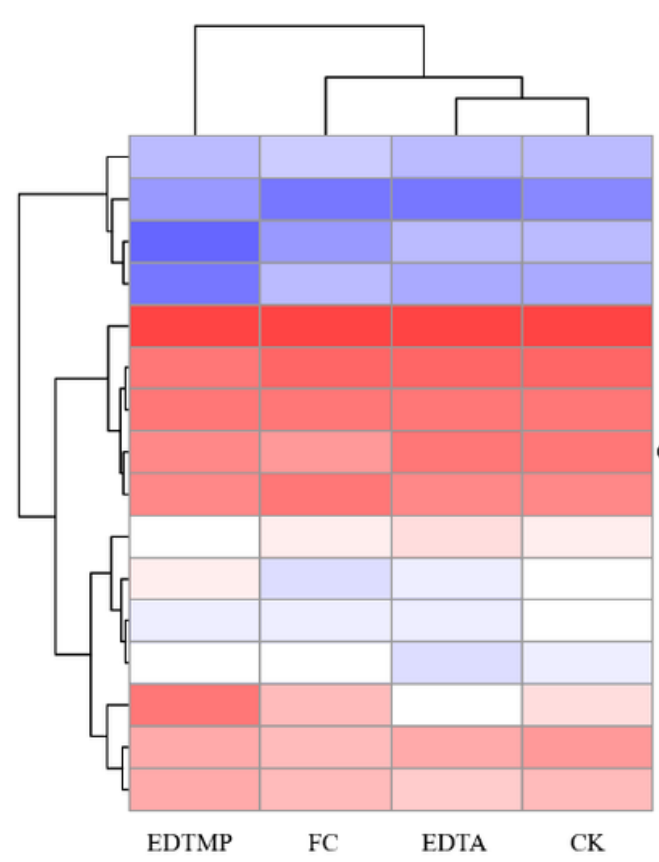

(a)

Elusimicrobia

Crenarchaeota

Chlorobi

Fibrobacteres

Proteobacteria

Acidobacteria

Chloroflexi

Gemmatimonadetes

Actinobacteria

Nitrospirae

Verrucomicrobia

Armatimonadetes

Cyanobacteria

Firmicutes

Bacteroidetes

Planctomycetes

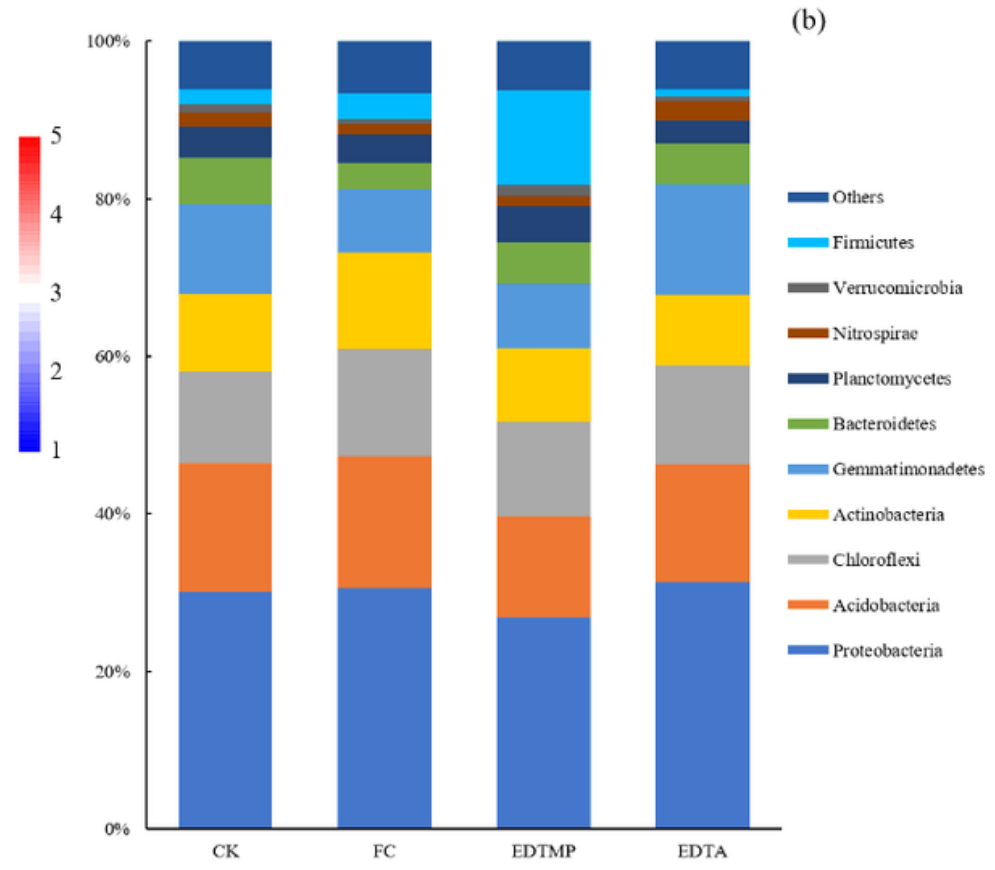

Figure 3

Heat map(a) and relative abundance of different bacteria(b) at phylum level. A rectangle represented a bacterium (at the phylum level). The redder the rectangle, the higher the relative abundance of bacteria. On the contrary, the bluer the rectangle, the lower the relative abundance
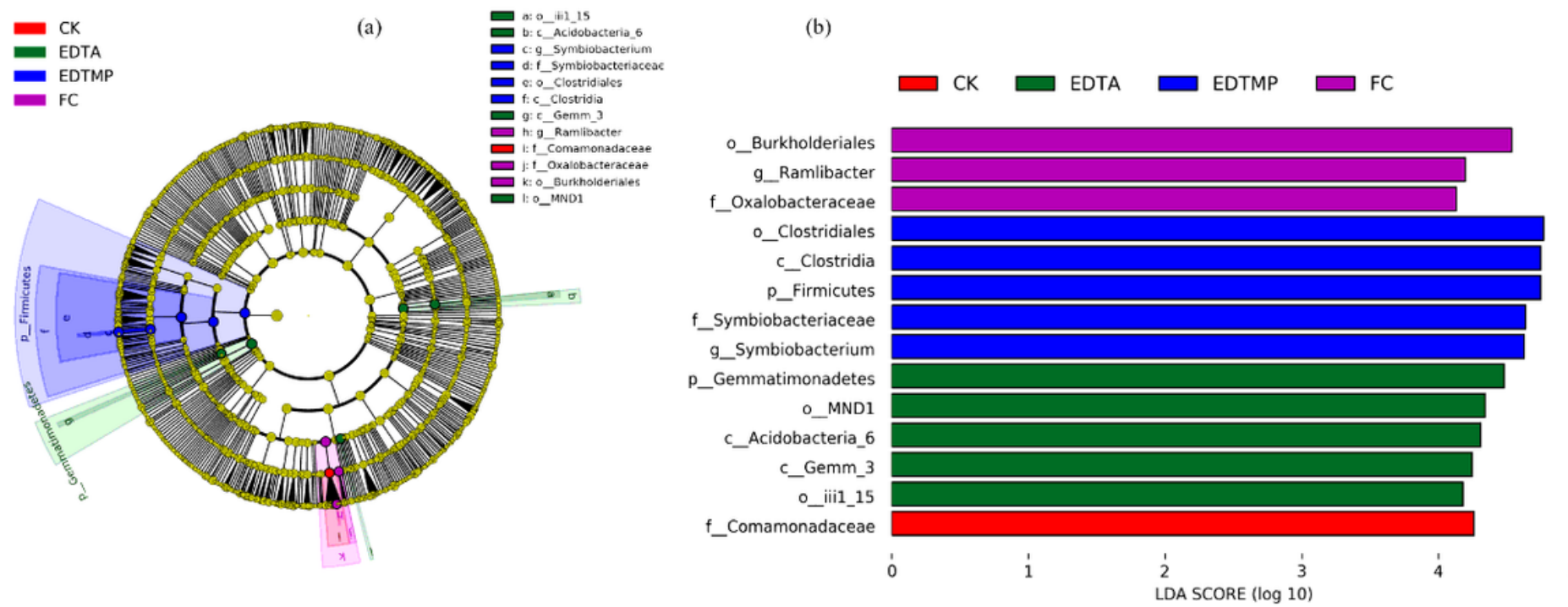

Figure 4 
LEfSe and LDA analysis based on OTUs of four treatments. (a) Cladogram showed the biomarker microbes of the microbial lineages from domain to genus among four different treatments. Yellow dot represented the microbes with no statistical differences among four treatments; (b) LDA scores showing the significant bacterial difference between four treatments
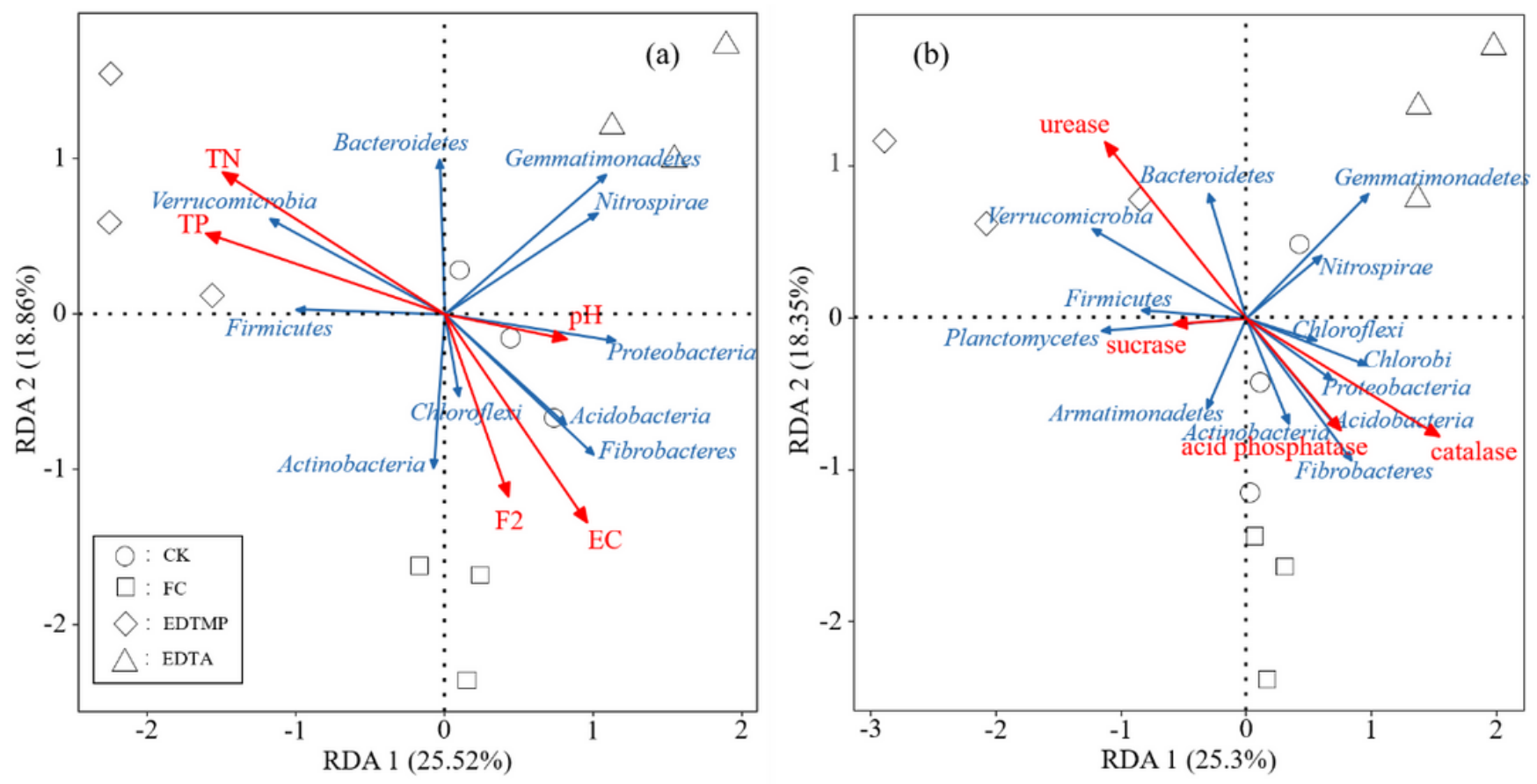

Figure 5

Redundancy analysis (RDA) for the relationship between environmental factors and microbial community(a) and the relationship between activities of the soil enzyme and bacteria community(b). represents CK treatment; $\square$ represents FC treatment; $\otimes$ represents EDTMP treatment and $\Delta$ represents EDTA treatment 